\title{
Characterization of pyoverdine and achromobactin in Pseudomonas syringae pv. phaseolicola 1448a
}

\author{
Jeremy G Owen ${ }^{1,2}$ and David F Ackerley ${ }^{1 *}$
}

\begin{abstract}
Background: Pseudomonas syringae pv. phaseolicola 1448a (P. syringae 1448a), the causative agent of bean halo blight, is a bacterium capable of occupying diverse biological niches. Under conditions of iron starvation $P$. syringae 1448a secretes siderophores for active uptake of iron. The primary siderophore of $P$. syringae 1448a is pyoverdine, a fluorescent molecule that is assembled from amino acid precursors by non-ribosomal peptide synthetase (NRPS) enzymes. Whereas other species of Pseudomonas often exhibit structural variations in the pyoverdine produced by different strains, all P. syringae pathovars previously tested have been found to make an identical pyoverdine molecule. P. syringae 1448a also appears to have the genetic potential to make two secondary siderophores, achromobactin and yersiniabactin, each of which has previously been detected in different $P$. syringae pathovars.

Results: Five putative pyoverdine NRPS genes in P. syringae 1448a were characterized in-silico and their role in pyoverdine biosynthesis was confirmed by gene knockout. Pyoverdine was purified from $P$. syringae 1448a and analyzed by MALDI-TOF and MS/MS spectroscopy. Peaks were detected corresponding to the expected sizes for the pyoverdine structure previously found in other P. syringae pathovars, but surprisingly $P$. syringae 1448a appears to also produce a variant pyoverdine species that has an additional 71 Da monomer incorporated into the peptide side chain. Creation of pyoverdine null mutants of $P$. syringae 1448a revealed that this strain also produces achromobactin as a temperature-regulated secondary siderophore, but does not appear to make yersiniabactin. Pyoverdine and achromobactin null mutants were characterized in regard to siderophore production, iron uptake, virulence and growth in iron limited conditions.

Conclusions: This study provides the first evidence of a P. syringae pathovar producing a side chain variant form of pyoverdine. We also describe novel $I C_{50}$ and liquid CAS assays to quantify the contribution of different siderophores across a range of iron starvation conditions, and show that although achromobactin has potential to contribute to fitness its contribution is masked by the presence of pyoverdine, which is a significantly more effective siderophore. Neither pyoverdine nor achromobactin appear to be required for $P$. syringae 1448a to cause bean halo blight, indicating that these siderophores are not promising targets for crop protection strategies.
\end{abstract}

\section{Background}

Acquisition of iron is essential for growth of most bacteria. However, due to insolubility at neutral $\mathrm{pH}$ the bioavailability of iron is extremely low in most natural environments. To circumvent this problem many bacteria respond to iron starvation by synthesizing high affinity iron-chelating molecules known as siderophores.

\footnotetext{
* Correspondence: david.ackerley@vuw.ac.nz

'School of Biological Sciences, Victoria University of Wellington, Kelburn

Parade, PO Box 600, Wellington 6140, New Zealand

Full list of author information is available at the end of the article
}

These siderophores are secreted into the extra-cellular environment where they bind ferric iron and are then actively transported back into the cell via specific ferricsiderophore receptors [1]. Siderophores play a prominent role in the biology of fluorescent pseudomonads, a genus renowned for occupying a very wide range of environmental niches. Fluorescent pseudomonads synthesize the peptide-derived molecule pyoverdine as their primary siderophore, together with secondary siderophores that have lower affinity for iron [2]. Although pseudomonads are not obligate pathogens, many species

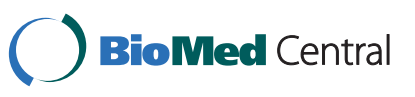


are capable of causing disease in a wide variety of hosts $[3,4]$. As iron restriction is a key host defense mechanism, pyoverdine is frequently implicated as an important virulence factor $[5,6]$.

Pyoverdine is synthesized from amino acid precursors by non-ribosomal peptide synthetase enzymes (NRPS) $[7,8]$. It is pyoverdine that provides the fluorescent Pseudomonas species with their defining fluorescence and yellow-green pigmentation under conditions of iron limitation [9]. These properties derive from an invariant dihydroxyquinoline chromophore, to which is attached an acyl moiety and a strain-specific peptide side chain [10]. More than 50 different pyoverdine structures have been described to date [11] and the variability of the peptide side chain of pyoverdines from different strains reflects rapid evolution of both the NRPS that synthesize this side chain and the outer membrane receptors that recognize ferric pyoverdine [12]. Analysis of the pyoverdine locus of different $P$. aeruginosa strains indicated that it is the most divergent region in the core genome and that its evolution has been substantially shaped by horizontal gene transfer $[12,13]$. The diversification of pyoverdine structures is particularly interesting when viewed in the context of NRPS manipulation experiments [14-16] - the wide variety of pyoverdine structures that has resulted from natural recombination of a limited pool of NRPS modules provides clues as to how nature has overcome the barriers that frequently limit artificial recombination of NRPS enzymes [16,17]. Moreover, the ability to detect pyoverdine production at nanomolar levels by UV-fluorescent screening [18] makes the pyoverdine synthetases potentially a very attractive model system to study NRPS recombination. However, in terms of providing 'raw material' for such work, the only biochemical analysis of a pyoverdine NRPS to date focused on the L-threonine incorporating enzyme PvdD of $P$. aeruginosa PAO1 [19]. In the work described here we aimed to expand this focus to the NRPS enzymes of another fluorescent pseudomonad, Pseudomonas syringae pv. phaseolicola 1448a (P. syringae 1448a), which secretes an alternative form of pyoverdine to PAO1.

During the course of this study, pyoverdine null mutants were generated, revealing that $P$. syringae $1448 \mathrm{a}$ (like $P$. syringae pathovars syringae $\mathrm{B} 728$ a [20], syringae $22 \mathrm{~d} / 93$ [21], and glycinea 1a/96 [21]) produces achromobactin as a secondary siderophore. In contrast to pyoverdine, achromobactin is synthesized by a mechanism that is entirely independent of NRPS enzymes [22]. NRPS-independent siderophores have been studied far less intensively than their NRPS-dependent counterparts, and their mechanisms of synthesis have only recently begun to be deciphered. Three types (A, B and C) of NRPS-independent siderophore synthetase enzymes have been identified to date, each responsible for the attachment of a different functional group to a citric acid backbone $[22,23]$. The achromobactin biosynthetic pathway is a particularly valuable resource for the study of these enzymes as it relies on the action of all three types of synthetase [22,24]. Achromobactin has been shown to be important for virulence in Dickeya dadantii (formerly Erwinia chrysanthemi) [25], and both pyoverdine and achromobactin contribute to epiphytic fitness of $P$. syringae pv. syringae $22 \mathrm{~d} / 93$ [21], but the contribution of siderophores to virulence of $P$. syringae 1448a has not previously been characterized. We therefore examined the roles of both achromobactin and pyoverdine in virulence of $P$. syringae 1448a, as well as their relative contribution to iron uptake and growth under more precisely defined conditions.

\section{Results}

Identification and in silico characterization of the $P$. syringae 1448a pyoverdine locus

The biosynthesis of pyoverdine has been most extensively studied in P. aeruginosa PAO1 and most, if not all, of the genes required for pyoverdine synthesis in this strain have now been identified $[6,10,26]$. Ravel and Cornelis [8] used the PAO1 pyoverdine genetic locus as a blueprint for annotation of the pyoverdine loci from three other fluorescent pseudomonads, including $P$. syringae pv. tomato DC3000. We adopted a similar strategy to interrogate the P. syringae 1448a genome, individually BLASTP searching all of the known PAO1 pyoverdine proteins against the $P$. syringae 1448a sequence database [27].

The genomic organization of pyoverdine genes in $P$. syringae 1448 a is highly similar to the $P$. syringae DC3000 genetic locus presented by Ravel and Cornelis [8], but less similar to that of PAO1 (Figure 1A, Table 1 ). Given the similarity with the P. syringae DC3000 genetic locus and the excellent earlier analysis of Ravel and Cornelis, we confine our analysis of the non-NRPS genes of $P$. syringae 1448a to two aspects not previously noted by them. The first concerns the only PAO1 gene that clearly lacks an ortholog in $P$. syringae, $p v d F$, which encodes an enzyme required for generating the $\mathrm{N}^{5}$-formyl- $\mathrm{N}^{5}$-hydroxyornithine residues that are present in the PAO1 (but not $P$. syringae) pyoverdine side chain. Instead, P. syringae 1448a contains a gene (Pspph1922; marked * in Figure 1A) that is $37 \%$ identical at a predicted protein level to the syrP gene of Pseudomonas syringae pv. syringae. Originally mis-annotated as a putative regulatory gene, SyrP has subsequently been shown to be an aspartate hydroxylase that is required for synthesis of the NRPS-derived phytotoxin syringomycin [28]. On this basis we propose that Pspph1922 very likely catalyzes $\beta$-hydroxylation of two hydroxyaspartate residues expected to be present in the $P$. 


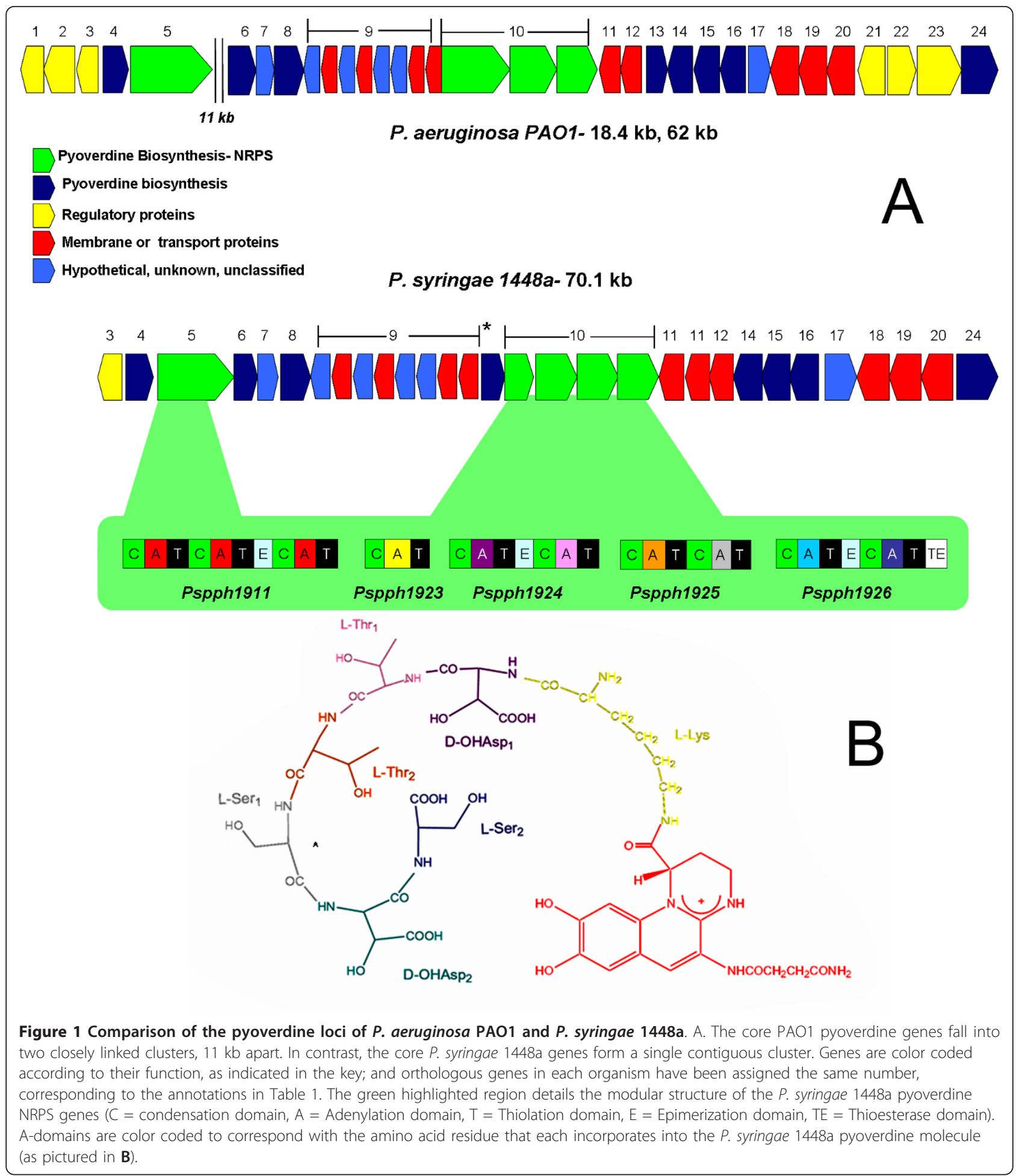

syringae 1448a pyoverdine side chain (Figure 1B), with equivalent iron-chelating roles to the $\mathrm{N}^{5}$-formyl- $\mathrm{N}^{5}$ hydroxyornithine residues of PAO1 pyoverdine. We also note that $P$. syringae 1448 a contains two orthologs of the PAO1 ferripyoverdine receptor gene $f p v A$. The predicted products of these genes share $52.5 \%$ amino acid identity with one another, and 35.5\% (Pspph1927) and $36.0 \%$ (Pspph1928) with FpvA from PAO1. PAO1 itself contains a second type I ferripyoverdine receptor gene, $f p v B$, whose product is $54 \%$ identical to FpvA [29]; 
Table 1 Summary of PAO1 and Ps1448a pyoverdine gene alignment results

\begin{tabular}{|c|c|c|c|}
\hline & $\begin{array}{l}\text { PAO1 } \\
\text { gene }\end{array}$ & Function in P. aeruginosa PAO1 & $\begin{array}{l}\text { Ps1448a ortholog } \\
(\mathrm{s})^{+}\end{array}$ \\
\hline 1 & $p v d Y$ & Regulatory protein & 1515 \\
\hline 2 & $p v d X$ & Regulatory protein & 3568 \\
\hline 3 & pvds & ECF iron sigma factor & 1909 \\
\hline 4 & $p v d G$ & Thioesterase (34\% identity with GrsT thioesterase from Bacillus brevis) & 1910 \\
\hline 5 & $p v d L$ & Chromophore peptide synthetase & 1911 \\
\hline 6 & pvdH & Aminotransferase & 1912 \\
\hline 7 & Pa2412 & MbtH-like protein (no known function) & 1913 \\
\hline 8 & Pa2411 & $\begin{array}{l}\text { Thioesterase ( } 36 \% \text { identity with thioesterase GrsT } \\
\text { from Bacillus brevis) }\end{array}$ & 1910 \\
\hline 9 & $\begin{array}{l}\mathrm{Pa} 2403- \\
2410\end{array}$ & $\begin{array}{l}\text { No known function, however expression of these genes is co-regulated with pyoverdine synthesis genes. } 2408 \\
\text { and } 2409 \text { are predicted to encode an ABC transporter }\end{array}$ & 1914-1921 \\
\hline * & $\begin{array}{l}\text { Not } \\
\text { present }\end{array}$ & (Likely pyoverdine aspartate hydroxylase of Ps1448a) & 1922 \\
\hline 10 & $p v d D I J$ & Pyoverdine side chain NRPS & 1923-1926 \\
\hline 11 & fpvA & Ferripyoverdine receptor protein & 1870, 1927, 1928 \\
\hline 12 & pvdE & ABC transporter (secretion) & 1929 \\
\hline 13 & $p v d F$ & N5-hydroxyornithine transformylase & Not present \\
\hline 14 & pvdO & No known function & 1930 \\
\hline 15 & $p v d N$ & $26 \%$ identity with isopenicillin N epimerase from Streptomyces clavuligerus & 1931 \\
\hline 16 & pvdM & Dipeptidase (23\% identity with porcine dipeptidase) & 1932 \\
\hline 17 & pvdP & No known function & 1933 \\
\hline 18 & Pa2391 & Porin (over 30\% identity with outer membrane factor (OMF) proteins of RND/MFP/OMF-type efflux systems) & 1934 \\
\hline 19 & Pa2390 & $\begin{array}{l}\text { ABC transporter (over } 40 \% \text { identity with resistance-nodulation-division (RND)-type transporter components of } \\
\text { RND/MFP/OMF-type efflux systems) }\end{array}$ & $1935 / m a c B$ \\
\hline 20 & Pa2389 & $\begin{array}{l}\text { Periplasmic protein (over } 30 \% \text { identity with periplasmic membrane fusion proteins (MFP) of RND/MFP/OMF-type } \\
\text { efflux systems) }\end{array}$ & 1936 \\
\hline 21 & $f p \vee R$ & Antisigma factor for PvdS and Fpvl & 2117,4764 \\
\hline 22 & fpvl & ECF sigma factor required for expression of fpvA & $\begin{array}{l}4765,1175,1093, \\
2747,1909\end{array}$ \\
\hline 23 & $p v d A$ & L-ornithine hydroxylase & 2415,3753 \\
\hline 24 & pvdQ & $\begin{array}{l}\text { Acylase ( } 38 \% \text { identity with Aculeacin A acylase from } \\
\text { Actinoplanes utahensis) }\end{array}$ & 1937 \\
\hline
\end{tabular}

†Gene numbers for Ps1448a are as annotated in the Pseudomonas genome database. Genes were presumed to be orthologs if they belonged to the same COG group. Hits are listed in order of significance, with those falling within the Ps1448a pyoverdine locus (as pictured in figure 1) listed in bold.

however in PAO1 this second ferripyoverdine receptor gene lies outside the pyoverdine locus.

$P$. syringae 1448 a also contains 5 NRPS genes that lie within the pyoverdine locus (Figure 1A). The gene Pspph1911 presumably governs synthesis of the pyoverdine chromophore, as it shares $72.4 \%$ predicted amino acid identity with the chromophore NRPS gene $p v d L$ of $P$. aeruginosa PAO1 and homologs of this gene are present in all fluorescent pseudomonads that have been examined [10,30,31]. Likewise, the four contiguous genes Pspph1923-1926 are expected to encode the side chain NRPS of P. syringae 1448a, and the total number of NRPS modules in these genes (7) corresponds exactly with the number of amino acids in the P. syringae 1448a pyoverdine side chain. Bioinformatic prediction of the substrate specificity of these modules (using the online NRPS analysis tool http://nrps.igs.umaryland.edu/nrps/
[32]) as well as heuristic prediction software [33] revealed that their likely substrates are (in linear order) L-Lys, D-Asp, L-Thr, L-Thr, L-Ser, D-Asp, L-Ser (Table 2) (stereospecificity being assigned on the basis of Edomain presence or absence in that module). Assuming $\beta$-hydroxylation of the two D-Asp residues as noted above, and the co-linearity that is typical of NRPS clusters [34], this substrate specificity is consistent with the linear order of residues identified in the pyoverdine side chains of several other $P$. syringae pathovars $[35,36]$ (Figure 1B).

\section{Mass spectrometry of pyoverdine purified from $P$. syringae $1448 \mathrm{a}$}

To test the in silico predictions above we purified the pyoverdine species secreted by $P$. syringae 1448 a using amberlite bead affinity chromatography as previously 
Table 2 In silico prediction of A-domain specificity for Ps1448a pyoverdine side chain NRPS

\begin{tabular}{|c|c|c|c|}
\hline A domain & 8 residue signature alignment & Identity of best match & TSVM prediction congruent? \\
\hline 1923 & $\begin{array}{l}\text { DGEDHGTV } \\
||||: \mid \\
\text { DAESIGSV }\end{array}$ & BacB-M1-Lys bacitracin synthetase 2 & No: val $=$ leu $=$ ile $=$ abu $=$ iva-like specificity \\
\hline 1924 mod1 & $\begin{array}{l}\text { DLTKIGHV } \\
\text { ||||: ||: } \\
\text { DLTKVGHI }\end{array}$ & SrfAB-M2-Asp surfactin synthetase B & $\begin{array}{l}\text { Yes: } \\
\text { asp }=\text { asn }=\text { glu }=\text { gln }=\text { aad-like specificity }\end{array}$ \\
\hline $1924 \bmod 2$ & $\begin{array}{l}\text { DFWNIGMV } \\
|||||||| \\
\text { DFWNIGMV }\end{array}$ & $\begin{array}{l}\text { PvdD-M2-Thr } \\
\text { pyoverdine synthetase }\end{array}$ & $\begin{array}{l}\text { Yes: } \\
\text { thr }=\text { dht-like specificity }\end{array}$ \\
\hline 1925 mod1 & $\begin{array}{l}\text { DFWNIGMV } \\
|||||||| \\
\text { DFWNIGMV }\end{array}$ & $\begin{array}{l}\text { PvdD-M2-Thr } \\
\text { pyoverdine synthetase }\end{array}$ & $\begin{array}{l}\text { Yes: } \\
\text { thr }=\text { dht-like specificity }\end{array}$ \\
\hline $1925 \bmod 2$ & $\begin{array}{l}\text { DVWHVSLI } \\
|||||||| \\
\text { DVWHVSLI }\end{array}$ & PvdJ-M1-Ser pyoverdine synthetase & $\begin{array}{l}\text { Yes: } \\
\text { ser-like specificity }\end{array}$ \\
\hline 1926 mod1 & $\begin{array}{l}\text { DLTKIGHV } \\
||||:||: \\
\text { DLTKVGHI }\end{array}$ & SrfAB-M2-Asp surfactin synthetase B & $\begin{array}{l}\text { Yes: } \\
\text { asp }=\text { asn }=\text { glu }=\text { gln }=\text { aad-like specificity }\end{array}$ \\
\hline 1926 mod2 & $\begin{array}{c}\text { DVWHWVSLI } \\
\text { DVWLI }\end{array}$ & PvdJ-M1-Ser pyoverdine synthetase & $\begin{array}{l}\text { Yes: } \\
\text { ser-like specificity }\end{array}$ \\
\hline
\end{tabular}

described [16]. Fractions were collected and analysed for siderophore activity by addition of chromeazurol $\mathrm{S}$ (CAS; a dye that is blue-green when complexed with iron and yellow when iron is removed from it) and the fraction with the highest activity was subjected to MALDI-TOF analysis to identify the mass of the primary constituents (Figure 2A). This revealed the presence of three major positive ion peaks. One of these peaks $(\mathrm{m} / \mathrm{z} 1141)$ is consistent with the linear (hydrolysed) pyoverdine structure portrayed in Figure 1B, while another $(\mathrm{m} / \mathrm{z} 1123)$ corresponds to the cyclized form observed in other P. syringae pathovars, in which an ester bond between the C-terminal carboxyl and the side chain of the second internal threonine residue results in a lactone structure [35]. The third peak $(\mathrm{m} / \mathrm{z}$ 1212), 71 mass units greater than linear pyoverdine, could not be explained by either the in silico characterization above or by comparison with the structures previously elucidated for other $P$. syringae pathovars. We hypothesized that this peak resulted from either a pyoverdine molecule bearing an alternative acyl substituent attached to the chromophore (71 Da larger than the succinate-derived moiety portrayed in Figure $1 \mathrm{~B}$ ) or a contaminant that had co-purified with pyoverdine.

To test this hypothesis, and to investigate the identity and order of the amino acids present in the pyoverdine side chain, the peaks at m/z 1141 and 1212 were subjected to MS/MS analysis. Fragmentation of the peak at $\mathrm{m} / \mathrm{z} 1141$ resulted in the formation of a set of $\mathrm{B}$ ions (Figure 2B, Table 3 ) that corresponded exactly to the order and identity of amino acids predicted in Figure 1B. In contrast, fragmentation of the peak at $\mathrm{m} / \mathrm{z} 1212$ resulted in a series of peaks with identical spacing and intensity to those in Figure 2B, but 71 Da larger (Figure $2 \mathrm{C}$, Table 4). This immediately discounted the possibility that the MALDI-TOF peak at m/z 1212 arose from sample contamination. Moreover, in both Figure $2 \mathrm{~B}$ and $2 \mathrm{C}$ there are peaks at $\mathrm{m} / \mathrm{z} 357$ (Tables 3 and 4), corresponding to the predicted mass of the pyoverdine chromophore with an attached acyl group derived from succinate. In both spectra there are also intense peaks that correspond a Y-ion (marked Y1, Figure 2B, C) formed as a result of loss of the acyl group from the chromophore; and these peaks also differ by $71 \mathrm{Da}$. Together, these results suggest that the variant pyoverdine species differs from that portrayed in Figure 1B not in the structure of its chromophore, but rather in the constitution of its polypeptide side chain. Finally, we note that there is a fourth, smaller peak at $\mathrm{m} / \mathrm{z} 1194$ in the MALDI-TOF spectrum (Figure 2A), which may correspond to a cyclized form of this larger pyoverdine species.

\section{Genetic and biochemical analysis of the pyoverdine NRPS} genes

To confirm that each of the putative pyoverdine NRPS genes was indeed required for pyoverdine biosynthesis, these were individually deleted in-frame from the chromosome using a rapid overlap PCR-based method $[37,38]$. When grown on iron-limiting King's B (KB) media [39] each NRPS gene deletion strain lacked the UV fluorescence of wild type (WT) (Figure 3A). Likewise, each of the gene deletion strains was impaired in siderophore production, assessed following $24 \mathrm{~h}$ growth 

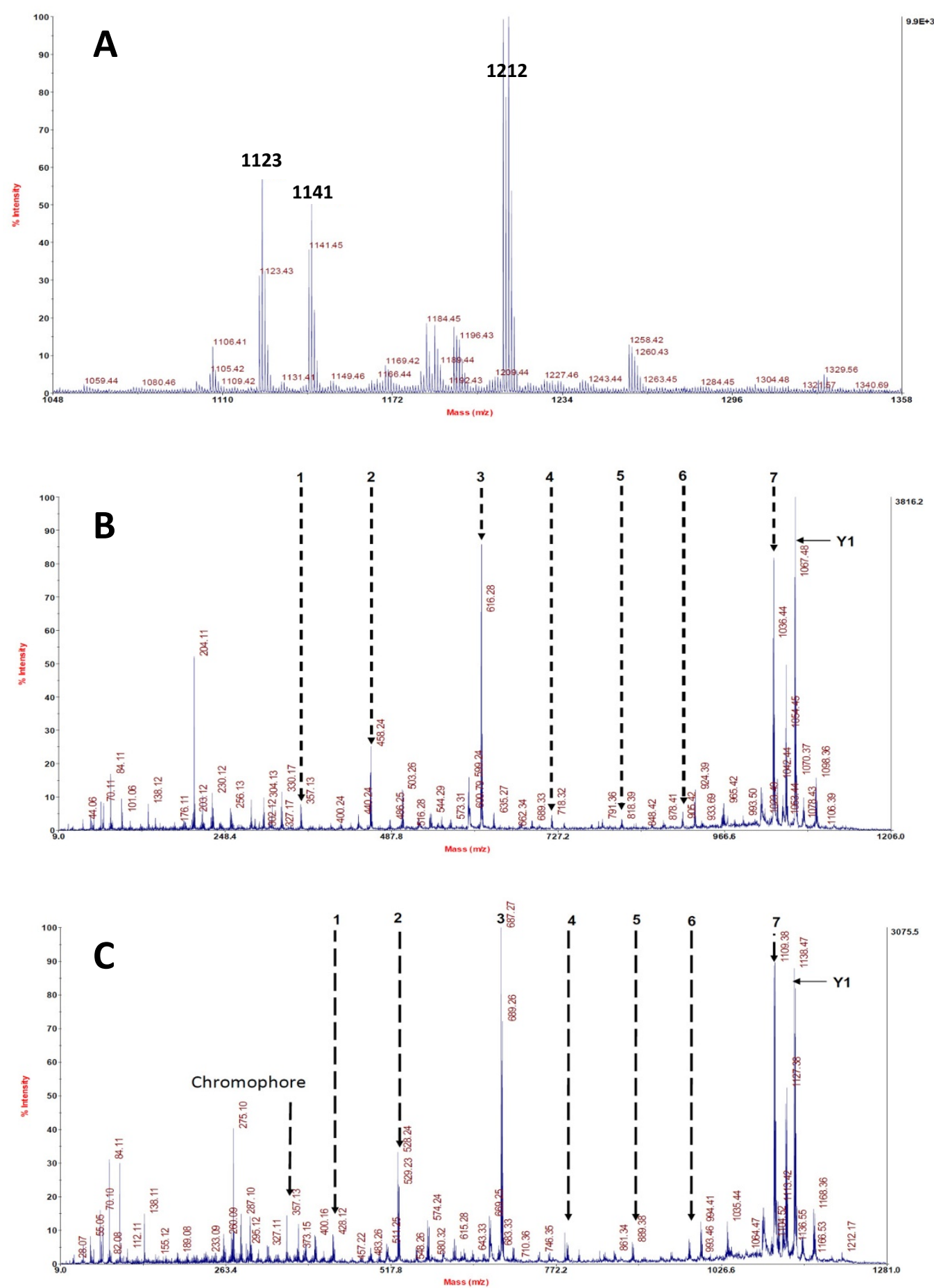

Figure 2 Mass spectral analysis of pyoverdine purified from P. syringae 1448a. A. MALDI-TOF analysis showing three major $[\mathrm{M}+\mathrm{H}]+\mathrm{species}$. lons corresponding to cyclic $(\mathrm{m} / \mathrm{z}=1123)$ and linear $(\mathrm{m} / \mathrm{z}=1141)$ pyoverdine are present along with a third variant species $(\mathrm{m} / \mathrm{z}=1212)$. B. MS/MS analysis of $\mathrm{m} / \mathrm{z}=1141$ precursor; masses and putative identity of indicated peaks are presented in Table 3. C. MS/MS analysis of $\mathrm{m} / \mathrm{z}=1212$ precursor showing a set of fragment ions 71 Da heavier than those indicated in part B (masses presented in Table 4). 
Table 3 Negative ions arising from MS/MS analysis of the $\mathrm{m} / \mathbf{z}=\mathbf{1 1 4 1}$ pyoverdine species

\begin{tabular}{lll}
\hline $\begin{array}{l}\text { Peak } \\
\text { number }\end{array}$ & Mass & Composition of ion \\
\hline 1 & 357.13 & B ion: CHR \\
2 & 458.24 & B ion: CHR_K \\
3 & 616.28 & B ion: CHR_K_OH-D \\
4 & 718.32 & B ion: CHR_K_OH-D_T \\
5 & 818.39 & B ion: CHR_K_OH-D_T_T \\
6 & 905.42 & B ion: CHR_K_OH-D_T_T_S \\
7 & 1036.41 & B ion: CHR_K_OH-D_T_T_S_OH-D \\
Y1 & 1067.48 & Y ion resulting from loss of chromophore acyl \\
& & group
\end{tabular}

Fragmentation of the $\mathrm{m} / \mathrm{z}=1141$ pyoverdine species resulted in identification of the following negative ions as shown in Figure 2B. Peaks 1-7 match the expected pattern of B-ions previously reported for fragmentation of other $\mathrm{P}$. syringae linear pyoverdine molecules. $Y 1$ has the expected mass for the $Y$ ion resulting from loss of the acyl group of the chromophore. $\mathrm{CHR}=$ chromophore, $\mathrm{OH}-\mathrm{D}=$ hydroxyaspartate, all other amino acids indicated by standard one letter code.

on CAS agar plates at $28^{\circ} \mathrm{C}$ (Figure $3 \mathrm{~B}$ ); and was unable to grow on $\mathrm{KB}$ agar plates containing $200 \mu \mathrm{g} / \mathrm{ml}$ EDDHA (ethylene-diamine-di-hydroxyphenylacetic acid, an iron chelating agent that establishes a strong selective pressure for effective siderophore-mediated iron transport; Figure 3C). These phenotypes confirmed that none of the gene deletion strains were able to produce pyoverdine. Successful restoration of pyoverdine synthesis by complementation in trans indicated that these phenotypes did not result from polar effects. Restoration of pyoverdine synthesis was demonstrated through the reestablishment of UV fluorescence and the ability to grow on $\mathrm{KB}$ agar plates containing $200 \mu \mathrm{g} / \mathrm{ml}$ EDDHA (Figure 3C), as well as a positive phenotype on solid and liquid media CAS assays (not shown).

Table 4 Negative ions arising from MS/MS analysis of the $\mathrm{m} / \mathrm{z}=1212$ pyoverdine species

\begin{tabular}{lll}
\hline $\begin{array}{l}\text { Peak } \\
\text { number }\end{array}$ & Mass & $\begin{array}{l}\text { Mass difference with equivalent peak in } \\
\text { Table 3 }\end{array}$ \\
\hline CHR & 357.13 & 0 \\
1 & 428.12 & 70.99 \\
2 & 529.23 & 70.99 \\
3 & 687.27 & 70.99 \\
4 & 789.30 & 70.98 \\
5 & 889.38 & 70.99 \\
6 & 976.43 & 71.01 \\
7 & 1107.40 & 70.99 \\
$Y 1$ & 1138.47 & 70.99 \\
\hline
\end{tabular}

Fragmentation of the $\mathrm{m} / \mathrm{z}=1212$ pyoverdine species resulted in identification of the following negative ions as shown in Figure $2 \mathrm{C}$. The numbering and spacing of ions is identical to those listed in Table 3, but with peak 1 now representing the chromophore bearing an unknown 71 Da substituent. Y1 has the expected mass for the $Y$ ion resulting from loss of the acyl group of the chromophore (allowing for the unknown 71 Da substituent).
To confirm the pyoverdine NRPS substrate specificity assigned by in silico analysis, and also to investigate the possibility that relaxed substrate specificity for one of the NRPS modules might explain the presence of a variant pyoverdine species, we sought to express and purify each side chain module as a heterologous His6-tagged protein from Escherichia coli for biochemical characterization. However we were unable to recover any proteins that were functional in substrate specificity assays, despite managing to obtain soluble protein for full modules as well as isolated A-domains by several different methods (including low temperature growth in the presence of $2.5 \mathrm{mM}$ glycine betaine and 1 M D-sorbitol, a strategy that previously enabled us to isolate functional recombinant PvdD from P. aeruginosa PAO1 [19]; and over-expression and purification of recombinant proteins in the native P. syringae 1448a host). In contrast, we were able to express and purify two functional single-module NRPS control proteins, EntF from E. coli and BpsA from Streptomyces lavendulae [40].

\section{Characterization of achromobactin as a secondary siderophore of $P$. syringae 1448 a}

Although the pyoverdine deficient $\left(\mathrm{pvd}^{-}\right)$strains were unable to discernibly alter the color of the CAS dye during $24 \mathrm{~h}$ growth on agar at $28^{\circ} \mathrm{C}$ (Figure 3B), i.e. no active iron sequestration was apparent within this timeframe, some color change was observed when these plates were subsequently left at room temperature or maintained at $28^{\circ} \mathrm{C}$ for an extended duration. These observations suggested that the $\mathrm{pvd}^{-}$strains were secreting at least one alternative siderophore. Production of the secondary siderophore(s) appeared to be temperature dependent, with the $\mathrm{pvd}^{-}$strains exhibiting greater iron uptake at $22^{\circ} \mathrm{C}$ than at $28^{\circ} \mathrm{C}$ (the latter being the optimal laboratory temperature for growth of $P$. syringae 1448a [41]) (Figure 4A, B). However, none of the $\mathrm{pvd}^{-}$ strains were able to grow during $72 \mathrm{~h}$ incubation at either temperature on solid media containing $200 \mu \mathrm{g} / \mathrm{ml}$ EDDHA, indicating that the secondary siderophore(s) had much lower affinity than pyoverdine for iron.

To identify candidate genes governing synthesis of this secondary siderophore, some known siderophore synthetase sequences from other phytopathogenic bacteria were aligned by BLASTP against the $P$. syringae 1448 a genome $[27,42]$. This search revealed that $P$. syringae 1448 a contains gene clusters that are highly conserved (containing the same number and order of homologous genes) with the achromobactin biosynthetic locus of $P$. syringae pv. syringae B728a [20] and the yersiniabactin biosynthetic locus of P. syringae pv. tomato DC3000 [43].

To investigate the role of these gene clusters the $P$. syringae 1448a acsA (achromobactin biosynthesis [20]) and hmwp1 (yersiniabactin biosynthesis [43]) homologs were 


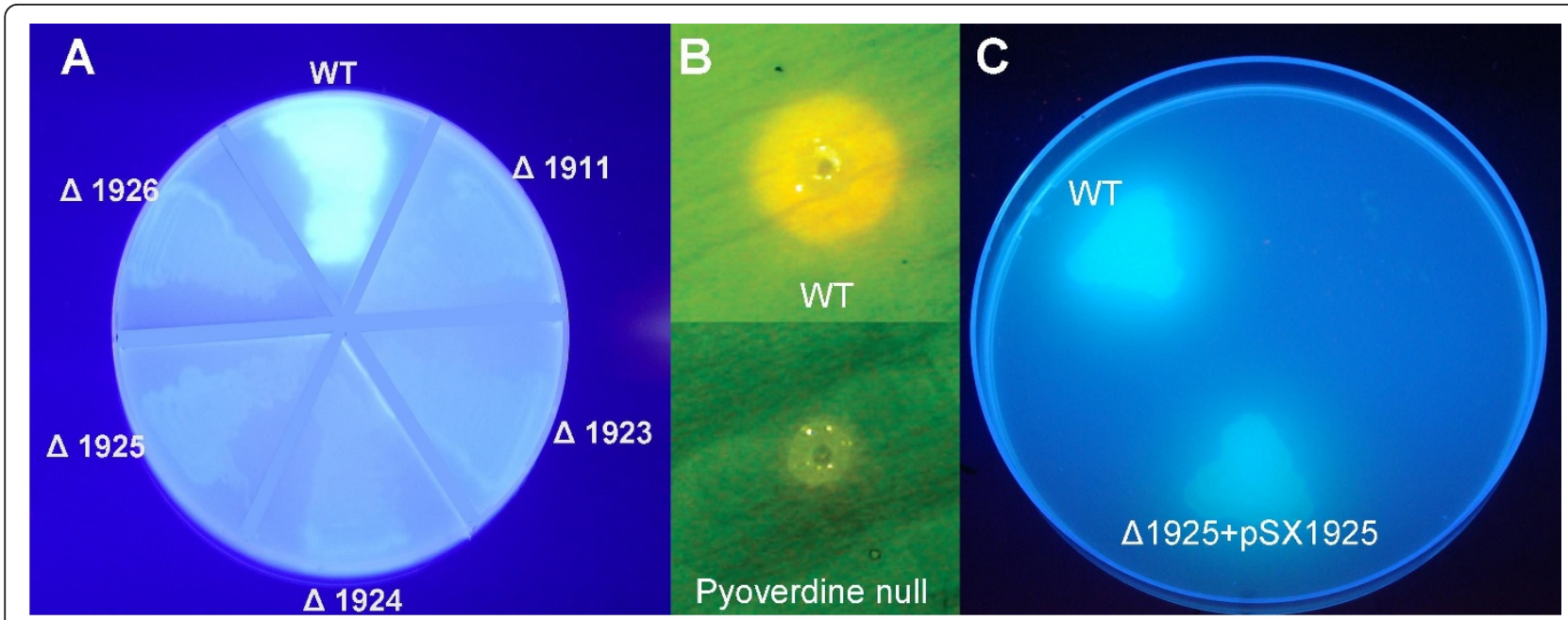

Figure 3 Characterization of $\boldsymbol{P}$. syringae 1448 a pyoverdine NRPS knockouts. A. Wild type (WT) and pyoverdine NRPS knockouts ( $\triangle 1911$, $\triangle 1923-1926)$ on iron-limiting KB agar viewed under UV light. Only the wild type is able to synthesize fluorescent pyoverdine. Pyoverdine gene knockout strains are named according to the gene deleted, based on the Pspph gene numbering scheme in the published genome database [27]. B. Wild type and pyoverdine null strain ( $\triangle 1925)$ inoculated into KB agar containing CAS dye and incubated for $24 \mathrm{~h}$ at $28^{\circ} \mathrm{C}$. Only the wild type strain took up discernible levels of iron as evidenced by the orange halo surrounding this inoculum. All pyoverdine NRPS knockouts exhibited indistinguishable iron transport deficient phenotypes. C. Wild type, $\Delta 1925$ and $\triangle 1925$ complemented by pSX:1925 on iron-restricted KB agar containing $200 \mu \mathrm{g} / \mathrm{ml}$ EDDHA. Complementation by a functional gene copy in trans restored pyoverdine synthesis to near wild type levels in each of the NRPS knockout strains.

deleted in-frame from both WT and $\mathrm{pvd}^{-}$strains of $P$. syringae 1448a. On solid media both the achromobactin ( $\mathrm{acr}^{-}$ ) and yersiniabactin ( $\left.\mathrm{ybt}^{-}\right)$single mutants were indistinguishable in phenotype from wild type, growing effectively in the presence of $200 \mu \mathrm{g} / \mathrm{ml}$ EDDHA and rapidly taking up iron on CAS agar. In contrast, a $\mathrm{pvd}^{-} / \mathrm{acr}^{-}$double mutant was unable to take up any discernible amounts of iron on CAS agar irrespective of the duration or

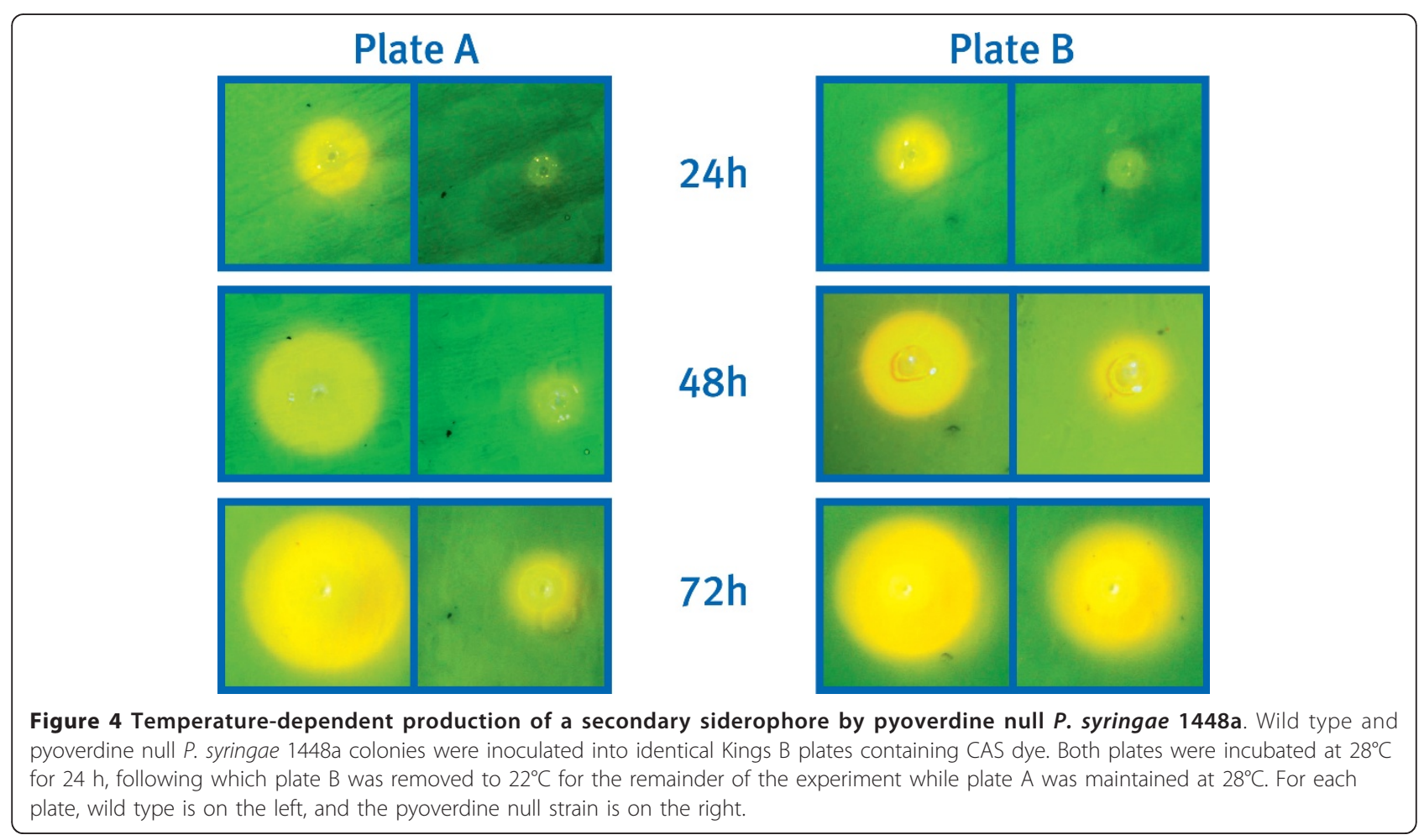


temperature of incubation (after $72 \mathrm{~h}$ at either 22 or $28^{\circ} \mathrm{C}$ $\mathrm{pvd}^{-} / \mathrm{acr}^{-}$colonies on CAS agar appeared identical to the $24 \mathrm{~h} \mathrm{pvd}^{-}$mutant pictured in Figure 3B). Using silica chromatography as previously described [20] we were able to isolate a siderophore from a culture of $\mathrm{pvd}^{-} P$. syringae 1448a grown to stationary phase in iron-limiting M9 minimal medium. When the fraction with the greatest siderophore activity (determined by addition of CAS dye) was analysed by MALDI-TOF, major peaks at m/z 590.2 and 572.2 were detected (not shown). The larger peak is consistent with the published mass for achromobactin of $590.15 \mathrm{Da}[20]$; while the smaller peak most likely represents the same species following loss of a water molecule when the same fraction was evaporated to dryness then resuspended in solvent prior to analysis, the relative intensity of the peak at m/z 572.2 substantially increased.

Surprisingly, despite appearing to have the genetic potential to make yersiniabactin, $P$. syringae 1448 a does not appear to produce any high-affinity siderophores other than pyoverdine and achromobactin. We were unable to observe any secretion of yersiniabactin by the $\mathrm{pvd}^{-} / \mathrm{acr}^{-}$double mutant and a $\mathrm{pvd}^{-} / \mathrm{acr}^{-} / \mathrm{ybt}^{-}$triple mutant was indistinguishable from the $\mathrm{pvd}^{-} / \mathrm{acr}^{-}$double mutant in all phenotypic assays conducted in this work. To test whether laboratory passage of our $P$. syringae 1448a strain might have resulted in inactivation of the yersiniabactin genes by phase-shifting or another reversible mechanism, we repeatedly sub-cultured the $\mathrm{pvd}^{-} /$ acr $^{-}$double mutant in iron-limiting KB broth on a daily basis for 7 days, each day plating out a dilution that gave ca. $10^{3}$ colonies on CAS agar. Duplicate plates were incubated at either $22^{\circ} \mathrm{C}$ or $28^{\circ} \mathrm{C}$ for up to $72 \mathrm{~h}$, but no siderophore-secreting colonies were recovered. We therefore concluded that $P$. syringae 1448 a produces only two high-affinity siderophores in response to iron deprivation, pyoverdine and achromobactin.

When each of the WT, $\mathrm{pvd}^{-}, \mathrm{acr}^{-}$, and $\mathrm{pvd}^{-} / \mathrm{acr}^{-}$ strains were grown in liquid media and subjected to a modified CAS assay that we developed to measure iron acquisition by factors secreted into the culture supernatant, the results were consistent with the phenotypes observed for each strain on CAS agar (Figure 5). These results confirmed that $P$. syringae $1448 \mathrm{a}$ is able to employ achromobactin as a temperature-regulated secondary siderophore that is secreted into the extracellular environment for active uptake of iron; but also suggested that the presence of pyoverdine is able to mask any phenotypic effects due to achromobactin alone.

\section{Assessment of relative fitness of mutant strains under iron starvation conditions}

To more precisely quantify the contribution of each siderophore under varying degrees of iron starvation, a serial dilution experiment was performed, employing EDDHA concentrations diluted 1:2 from $800 \mu \mathrm{g} / \mathrm{ml}$ down to $0.2 \mu \mathrm{g} / \mathrm{ml}$ in $\mathrm{KB}$ media in a 96-well plate. The WT, $\mathrm{pvd}^{-}$, acr', and $\mathrm{pvd}^{-} / \mathrm{acr}^{-}$strains were replica-inoculated into each well and incubated with shaking at $22^{\circ} \mathrm{C}$ for $24 \mathrm{~h}$, following which culture turbidity was measured. $\mathrm{IC}_{50}$ values (indicating the concentration of EDDHA that yielded only $50 \%$ turbidity relative to the unchallenged control) were calculated for each of the strains using Sigma Plot. The $\mathrm{IC}_{50}$ for the WT $(260 \pm$

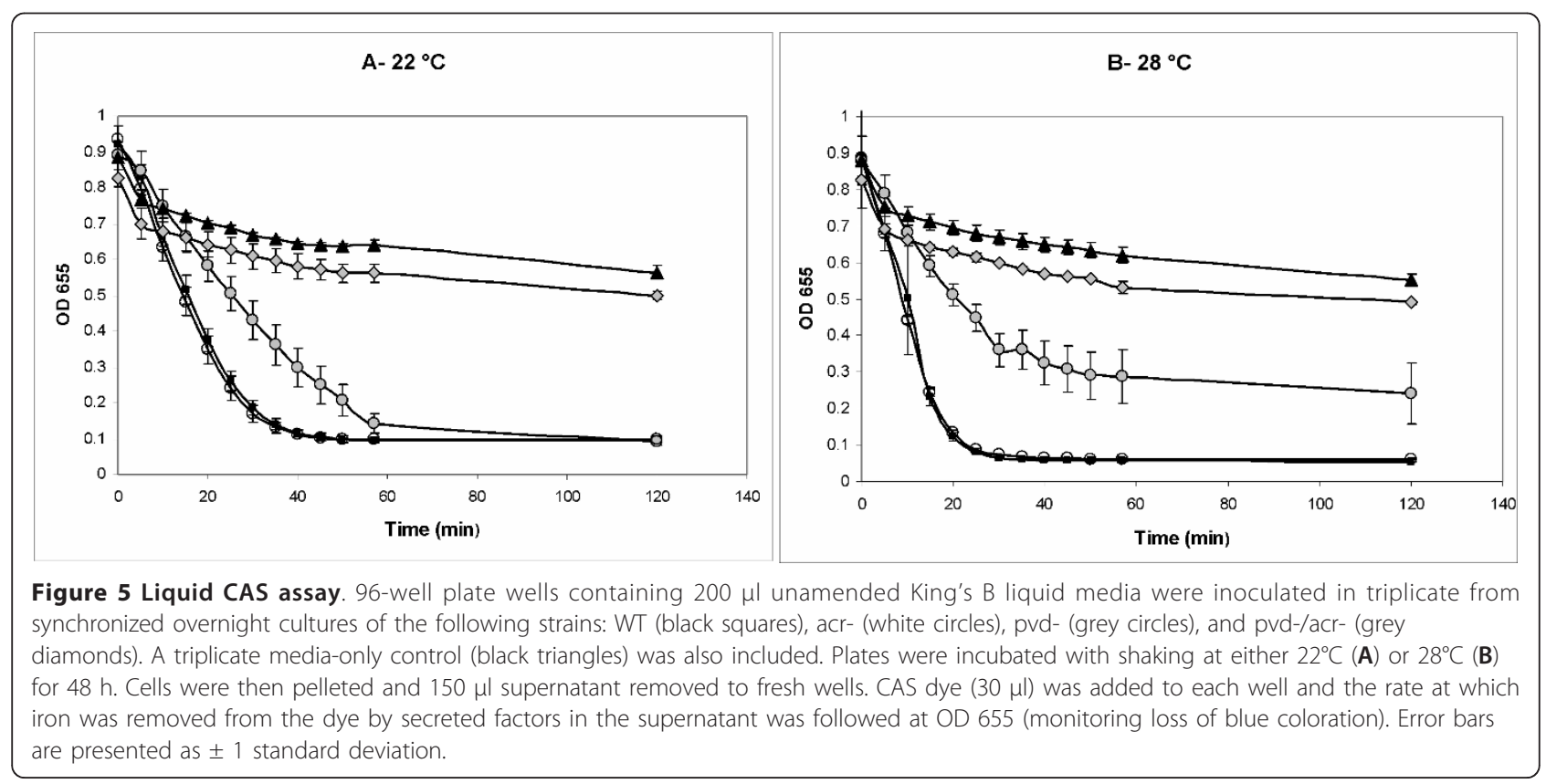


$50 \mu \mathrm{g} / \mathrm{ml})$ and $\operatorname{acr}^{-}(220 \pm 70 \mu \mathrm{g} / \mathrm{ml})$ strains were approximately equal, confirming that pyoverdine is able to compensate for achromobactin deficiency. In contrast the $\mathrm{pvd}^{-}$strain was sensitive to almost 3 orders of magnitude less EDDHA, with an $\mathrm{IC}_{50}$ of only $0.57 \pm 0.02$ $\mu \mathrm{g} / \mathrm{ml}$, demonstrating that achromobactin cannot completely compensate for the absence of pyoverdine. However, the $\mathrm{IC}_{50}$ for the $\mathrm{pvd}^{-} / \mathrm{acr}^{-}$double mutant strain $(0.31 \pm 0.01 \mu \mathrm{g} / \mathrm{ml})$ was reproducibly lower yet, verifying that in the absence of pyoverdine achromobactin still makes a small contribution to fitness during iron starvation. At $28^{\circ} \mathrm{C}$ the $\mathrm{IC}_{50}$ for $\mathrm{WT}$ and acr $^{-}$strains were essentially unchanged, but the difference between the $\operatorname{pvd}^{-}$mutant $(0.38 \pm 0.01)$ and $\mathrm{pvd}^{-} / \mathrm{acr}^{-}$double mutant $(0.26 \pm 0.01)$ was less marked.

\section{Assessment of pathogenicity in Phaseolus vulgaris}

In order to assess the pathogenicity in the natural host of $P$. syringae 1448a each of the mutant strains (including the $\mathrm{pvd}^{-} / \mathrm{acr}^{-} / \mathrm{ybt}^{-}$triple mutant) was subjected to the standard 'bean prick' pathogenicity test using bean pods [44]. All mutant strains were still able to cause characteristic water soaked lesions after inoculation and incubation in bean pods (Figure 6), irrespective of temperature and whether or not the beans were picked or still attached to the parental plant. This indicates that neither pyoverdine nor achromobactin is essential in enabling $P$. syringae 1448 a to cause halo blight in the bean plant Phaseolus vulgaris.

\section{Discussion}

Unlike $P$. aeruginosa, $P$. syringae does not appear to exhibit a high degree of variability in pyoverdine structure from strain to strain, with all fluorescent $P$. syringae pathovars tested thus far having been found to produce an identical pyoverdine molecule [35,36]. Our bioinformatic studies suggested that $P$. syringae 1448 a would not be any different in this regard; and MALDI-TOF and MS/MS analyses demonstrated that the same pyoverdine is indeed made by this strain. However, these analyses also indicated that $P$. syringae $1448 \mathrm{a}$ is able to make an additional pyoverdine variant that was fundamentally similar in most aspects, but with an overall mass 71 Da greater.

The most plausible interpretation of the fragmentation pattern in Figure $2 \mathrm{C}$ is that an extra monomer is incorporated into the pyoverdine side chain. If so, the B-ion pattern suggests that this monomer appears as the first residue of the side chain, falling between the chromophore and L-lysine, and increasing the mass by $71 \mathrm{Da}$. The only amino acid which could give this mass increase is alanine (free molecular mass of $89 \mathrm{Da} ; 71 \mathrm{Da}$ post-condensation). However, in silico analysis of all NRPS modules present in the genome of P. syringae 1448a failed to reveal any A-domains predicted to specify alanine. One possibility may be that the variant pyoverdine species was generated as an artefact of the purification process through some unexplained mechanism; however, as the additional monomer clearly seems to fall between the chromophore and lysine residue rather than being added in a peripheral fashion, this explanation seems unlikely. An alternative explanation is that the product of P. syringae 1448a gene Pspph 1923 (the single-module NRPS predicted to incorporate Llysine; Table 2) may possess a dual activity that enables occasional incorporation of an additional alanine residue. Unfortunately we were unable to biochemically characterize the substrate specificity of this or any other of the pyoverdine NRPS modules in in vitro assays despite obtaining soluble protein by several different strategies, none of our purified proteins appeared to retain activity. This phenomenon is not uncommon for NRPS enzymes. We note however that in ongoing work we have verified the second module of Pspph1925 is indeed a serine-activating NRPS, as predicted by our in silico analysis (Table 2); when appropriate regions of this gene are swapped with the equivalent regions in module 2 of $P$. aeruginosa PAO1 $p v d D$ the substrate specificity of the recombinant gene product is converted from L-threonine [19] to L-serine, and a correspondingly modified pyoverdine product is produced (MJ Calcott, JG Owen, LW Martin, IL Lamont, DF Ackerley,

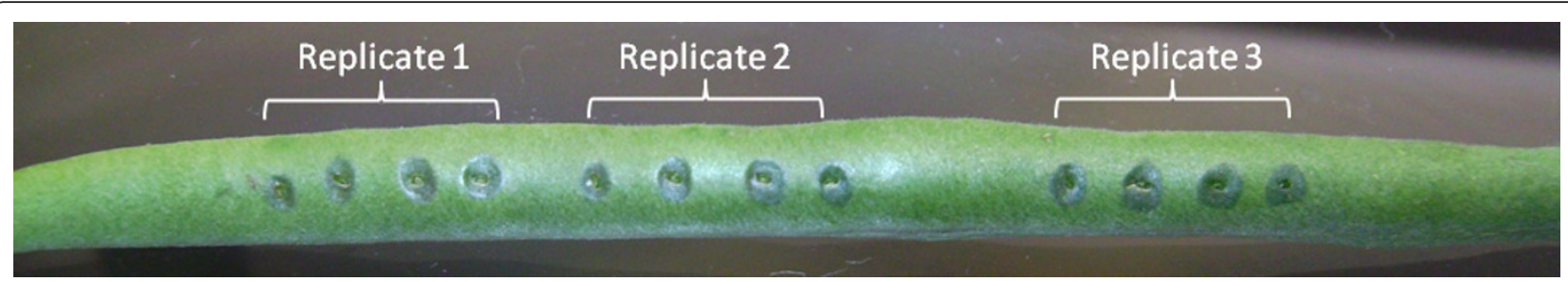

Figure 6 Assessment of pathogenicity of mutant strains in Phaseolus vulgaris. Three replicates are indicated each containing, in order from left to right, WT, pvd-, acr/pvd- and acr-/pvd-/ybt- strains. Each strain was inoculated from a single colony, using a hypodermic needle. The pod was then incubated in a humid chamber at room temperature for 48 hours. All strains display characteristic water-soaked lesions indicating successful establishment of pathogenicity in Phaseolus vulgaris. 
unpublished data). It may be that we can employ a similar 'recombinant genetic characterization' strategy to interrogate the substrate specificity of Pspph1923. However, for now the precise nature of the variant $P$. syringae 1448a pyoverdine species (peak $\mathrm{m} / \mathrm{z}$ 1212, Figure 2A) remains unknown. Although an equivalent species was not previously detected in studies of other $P$. syringae pathovars $[35,36]$, it is possible that these other pathovars also produce this form. As MALDI-TOF is not a quantitative technique the $\mathrm{m} / \mathrm{z} 1212$ peak may actually be a very minor species that happens to ionize particularly well; and as the previous studies utilized an HPLC preparative step to yield a single pure peak, this could conceivably have resulted in other minor peaks being missed. There is evidence from a previous isoelectric focusing analysis that different $P$. syringae pathovars produce minor variant isoforms of pyoverdine in addition to the major pyoverdine that is synthesized by all known fluorescent $P$. syringae isolates [45]. It is possible that the minor isoforms include variants that possess alternative side chain constituents as well as variants that have different acyl groups attached to the chromophore.

As per previous pyoverdine NRPS gene knockouts in fluorescent pseudomonads $[16,46]$, in-frame deletion of any of the chromophore or side chain NRPS genes in $P$. syringae 1448a resulted in complete abolition of pyoverdine synthesis. Analysis of these mutants under ironlimiting conditions revealed the presence of a secondary siderophore, which was shown by genetic and biochemical analysis to be achromobactin. Although P. syringae 1448 a also appears to have the genetic potential to produce a third siderophore, yersiniabactin, our $\mathrm{pvd}^{-} / \mathrm{acr}^{-}$ double mutant did not appear to be able to make this or any other siderophores, at least in response to iron limitation. Our study does not rule out that yersiniabactin synthesis might be induced in P. syringae 1448a in planta, but this would contrast with yersiniabactin synthesis in P. syringae pv. tomato DC3000, which occurs both in planta [46] and under iron-limiting conditions in vitro [43].

We observed that synthesis of achromobactin by our $\mathrm{pvd}^{-}$mutant was temperature sensitive. Temperature regulation of siderophore production has been observed for other bacterial species [47-49] and has been known to govern expression of other $P$. syringae genes, especially those implicated in causing disease [50]. Achromobactin is known to contribute to virulence in $D$. dadantii [25], and these observations prompted us to test whether it is a virulence factor in P. syringae 1448a also. The contribution of both achromobactin and pyoverdine to virulence of $P$. syringae 1448a during infection of Phaseolus vulgaris was assessed by inoculation of mutant strains and wild type controls into the bean pods. All single and double mutants were still able to cause lesions in this standardized pathogenicity test, indicating that neither siderophore is required for $P$. syringae 1448a to cause halo blight in Phaseolus vulgaris. These results were initially surprising to us, given that iron is essential for core metabolic processes, is believed to be severely restricted in the plant extracellular environment [51], and that siderophores are generally regarded as important for microbial pathogenesis of both plant and animal hosts [6,51]. However, although the assumption is frequently made that pyoverdines are able to act as virulence factors in both animal and plant hosts, there is little experimental evidence for the latter. Indeed, pyoverdine from $P$. syringae $p v$. syringae has likewise been shown not to have a determinative role in pathogenesis of sweet cherry fruit [52] and more recently, pyoverdine in $P$. syringae pv. tomato DC3000 has also been shown to be dispensable for pathogenesis [46]. It may be that phytotoxins render siderophores obsolete during the disease process by releasing iron from damaged plant cells into the extra-cellular environment. It should also be noted that the standard bean inoculation assay for $P$. syringae 1448 a virulence monitors only the ability to cause lesions, which is dependent primarily on toxin release and may not accurately report on the full progression of disease. Irrespective, it must be considered that any plant protection strategy which aims to target pyoverdine and/or achromobactin in $P$. syringae $p v$. phaseolicola will not prevent the appearance of economically-damaging halo blight lesions in bean crops.

Despite the lack of evidence for an active role in lesion formation, our phenotypic analyses of iron uptake and growth under iron limiting conditions confirmed that siderophores are indeed important for fitness of $P$. syringae 1448a during iron starvation. Although $P$. syringae has traditionally been defined as a phytopathogen, it is unclear how important pathogenicity really is to the survival of this bacterium in the wild [53]; and it may be that the P. syringae 1448a siderophores are more important for epiphytic survival on leaf surfaces, in soil or water than during infection. However, given the clear superiority of pyoverdine as a siderophore, it is unclear why $P$. syringae 1448 a makes achromobactin also. All of the fluorescent Pseudomonas species known apart from one exception (P. putida KT2440 [54]) synthesize at least one secondary siderophore and there is presumably some fitness benefit to be derived from this investment. There is evidence that secondary siderophores can have affinity for metals other than iron (reviewed by Cornelis [55]). The presence of orthologs of known nickel-transport genes immediately adjacent to the $P$. syringae 1448 a achromobactin cluster in the $P$. syringae 1448 a genome sequence [27] may be indicative of a similar 
role in this bacterium (although we were unable to discern any phenotypic effect of nickel addition or exclusion on achromobactin synthesis in the pvd mutant; not shown). It has also recently been shown that both primary and secondary siderophores (including the pyoverdine and pyochelin produced by $P$. aeruginosa [56]) can actually play defensive roles in sequestering toxic metals like aluminium, cobalt, copper and lead, which appears to protect bacteria against uptake of these metals by passive diffusion [57]. Independent of a direct role in metal transport or sequestration, it has been suggested that secondary siderophores can also be involved in various signaling pathways [55], or can have antimicrobial activities that are distinct from their iron scavenging properties [58].

Alternatively, Dominique Expert and co-workers have demonstrated that achromobactin in the phytopathogen $D$. dadantii is synthesized temporally before the primary NRPS-derived siderophore chrysobactin [25]; and have proposed that achromobactin in this bacterium may function as a provisional measure, enabling cells to respond more rapidly to fluctuations in iron availability while the slower chrysobactin system is established $[25,51]$. We suggest that a likely explanation for this scenario lies with the high energy investment required for activating NRPS mechanisms of siderophore synthesis. NRPS enzymes are amongst the largest known, with single proteins routinely exceeding $200 \mathrm{kDa}$ [59]. The energy requirements for a cell to synthesize such large proteins are substantial, and when already stressed this may represent a formidable barrier. However, once the NRPS enzymatic template is in place then it is an extremely efficient method for synthesizing short peptides, consuming significantly less ATP per peptide bond formed than ribosomal mechanisms [60]. It might therefore be useful to have a backup siderophore in place that can be expressed immediately in response to iron starvation and provide the cell with small amounts of iron while the NRPS template for the more efficient primary siderophore is established. As the phenotypes of our mutant strains indicate that achromobactin is only important when pyoverdine is not available, it is possible that achromobactin likewise serves as a 'first response' siderophore to cope with a sudden onset of iron starvation in P. syringae 1448a. Our investigation into the timing and regulation of pyoverdine and achromobactin synthesis in P. syringae 1448a is ongoing.

\section{Conclusions}

P. syringae 1448 a appears to have the genetic capacity to produce three different siderophores however only two of these, pyoverdine and achromobactin, were detectable as active siderophores under the various conditions examined. An essential role for five NRPS genes in pyoverdine synthesis was confirmed by gene deletion and complementation studies, and the in silico assignation of substrate specificity for each NRPS module was found to be congruent with a structure for $P$. syringae 1448a pyoverdine inferred from MS/MS data. Surprisingly, this data also indicated that $P$. syringae 1448a produces a second, heavier, isoform of pyoverdine, which may contain an extra alanine residue located between the chromophore and the lysine residue of the peptide side chain. Although pyoverdine was shown to be a substantially more effective siderophore than achromobactin, neither siderophore was found to play a definitive role in the ability of P. syringae 1448 a to cause halo blight, indicating that these siderophores are not promising targets for development of novel antibiotics to protect bean crops.

\section{Methods}

\section{Bioinformatics and computer programs}

Adenylation domain specificities for putative pyoverdine NRPS modules were predicted using the NRPS/ PKS predictor currently online at http://nrps.igs. umaryland.edu/nrps/, based on the 8 amino acid model of A domain prediction [32]. Specificities were also predicted using the TSVM method [33] with congruent results. For analysis of the pyoverdine cluster of $P$. syringae $1448 \mathrm{a}$, inferred amino acid sequences of known pyoverdine genes from $P$. aeruginosa PAO1 (as described in $[6,8]$ ) were aligned against the $P$. syringae 1448a genome using the default BLASTP settings of the Pseudomonas genome database http://www.pseudomonas.com[27]. Genes were taken to be orthologs if they were annotated as being in the same COG group; up to 5 matches were recorded where orthologous genes were not clearly present in the known pyoverdine locus and/or had a shared amino acid identity under $40 \%$. Annotated hits were then mapped onto the corresponding section of the P. syringae 1448a chromosome, derived from the Pseudomonas genome data base. This map was compared for accuracy against the map presented by Ravel and Cornelis [8], updated to include more-recently discovered $p v d$ genes, and a simplified version was used to generate Figure 1 . The pyoverdine structure for $P$. syringae 1448 a was adapted from Bultreys et al [35] and recreated and re-colored using the GIMP open office image manipulation software. Achromobactin and putative yersiniabactin genes were identified by BLASTP searching against the $P$. syringae 1448a genome using the corresponding protein sequences from $D$. dadantii [25] and P. syringae pv. tomato DC3000 [43], respectively. The putative function of the genes immediately surrounding the achromobactin cluster was derived from the annotations in the Pseudomonas genome database. 


\section{Bacterial strains, growth and maintenance}

The following bacterial strains were utilized in this study: rifampicin-resistant $P$. syringae 1448a, kindly provided by Professor John Mansfield [61]; and E. coli DH5 $\alpha \lambda$ pir (Invitrogen). P. syringae 1448a was routinely maintained at $28^{\circ} \mathrm{C}$ using $\mathrm{LB}$ or $\mathrm{KB}$ media. E. coli strains were maintained at $37^{\circ} \mathrm{C}$ using LB media. Aeration of liquid cultures was provided by shaking at $200 \mathrm{rpm}$. When necessary for plasmid or chromosomal antibiotic marker selection antibiotics were used at the following concentrations: rifampicin $50 \mu \mathrm{g} / \mathrm{ml}$, chloramphenicol $35 \mu \mathrm{g} / \mathrm{ml}$, gentamycin $20 \mu \mathrm{g} / \mathrm{ml}$.

\section{Purification and analysis of pyoverdine}

Pyoverdine purification was achieved using the method of Meyer et al [62]. Briefly, $200 \mathrm{ml}$ of standard M9 minimal medium, with succinic acid as the carbon source, was inoculated with $10 \mathrm{ml}$ acr $P$. syringae 1448a from a stationary phase culture grown in the same medium. The resulting culture was grown for $72 \mathrm{~h}\left(22^{\circ} \mathrm{C}, 200\right.$ $\mathrm{rpm})$ following which cells were removed by centrifugation $(5000 \mathrm{~g}, 30 \mathrm{~min})$. The supernatant was then sterilised by passing through a $0.22 \mu \mathrm{m}$ filter and the $\mathrm{pH}$ of the resulting $200 \mathrm{ml}$ culture supernatant adjusted to 6.0 with $\mathrm{cHCl}$. Approximately $40 \mathrm{cc}$ wet Amberlite XAD-4 resin (Supelco, PA), which had been previously activated according to the manufacturer's directions, was added to the acidified culture supernatant. The mixture was then shaken for $90 \mathrm{~min}$ at $200 \mathrm{rpm}$, after which the beads were discernibly green, indicating pyoverdine adsorption. The supernatant was then discarded and the beads

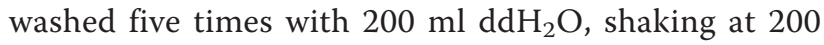
rpm for $15 \mathrm{~min}$. After this the beads were washed with

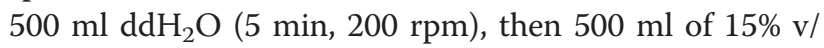
$\mathrm{v}$ methanol ( $5 \mathrm{~min}, 200 \mathrm{rpm}$ ). Pyoverdine was then removed from the beads by shaking with $100 \mathrm{ml}$ of $50 \%$ $\mathrm{v} / \mathrm{v}$ methanol $(200 \mathrm{rpm}, 2 \mathrm{~h}$ ) and the resulting solution freeze-dried. Purified pyoverdine was resuspended in 1

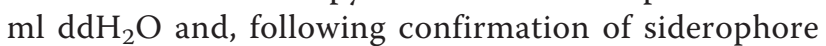
activity by CAS assay, sent to the Centre for Protein Research at the University of Otago for MALDI-TOF and MS/MS analysis.

\section{Purification and analysis of achromobactin}

The protocol for achromobactin purification was adapted from Berti and Thomas [20]. Briefly, $200 \mathrm{ml}$ of standard M9 minimal medium, with succinic acid as the carbon source, was inoculated with $10 \mathrm{ml} p v d^{-}$P. syringae 1448a from a stationary phase culture grown in the same medium. The resulting culture was grown for $72 \mathrm{~h}$ $\left(22^{\circ} \mathrm{C}, 200 \mathrm{rpm}\right)$ following which cells were removed by centrifugation (5000 g, $30 \mathrm{~min})$. The supernatant was then sterilised by passing through a $0.22 \mu \mathrm{m}$ filter and then the volume reduced to $20 \mathrm{ml}$ by rotary evaporation (temperature not exceeding $\left.45^{\circ} \mathrm{C}\right)$. Methanol $(180 \mathrm{ml})$ was then added, whereupon salt from the culture medium precipitated out of solution. Precipitate was removed by centrifugation (12,000 rcf, $20 \mathrm{~min})$ followed by filtration using a $0.45 \mu \mathrm{m}$ filter. The solution was then mixed 1:1 with ethyl acetate and $100 \mathrm{ml}$ of the resulting solution applied to a glass chromatography column containing $40 \mathrm{cc}$ silica beads pre-equilibrated with solvent A (9:1:10 v/v methanol: $\mathrm{H}_{2} \mathrm{O}$ :ethyl acetate). 100 $\mathrm{ml}$ Solvent A was then applied to the column, followed by $100 \mathrm{ml}$ solvent $\mathrm{B}\left(9: 1 \mathrm{v} / \mathrm{v}\right.$ methanol: $\left.\mathrm{H}_{2} \mathrm{O}\right)$. The elutate from the solvent $\mathrm{B}$ step was captured in $10 \mathrm{ml}$ fractions. Siderophore activity of the fractions was then assessed by adding $30 \mu \mathrm{L}$ CAS reagent to a $150 \mu \mathrm{L}$ aliquot of each fraction and incubating for $10 \mathrm{~min}$ at room temperature. The fraction which resulted in the greatest discolouration of the CAS dye was then reduced in volume to $2 \mathrm{ml}$ by rotary evaporation (temperature not exceeding $40^{\circ} \mathrm{C}$ ) and $1 \mathrm{ml}$ of the solution removed. The remaining $1 \mathrm{ml}$ was evaporated to dryness and resus-

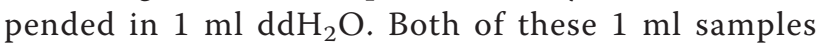
were then sent to the Centre for Protein Research at the University of Otago for MALDI-TOF analysis.

\section{Construction of gene knockout and over-expression plasmids}

Gene sequences were retrieved from the Pseudomonas genome database [27]. Primers were designed using Vector NTI (Invitrogen) to amplify $400 \mathrm{bp}$ regions from the 5' and 3' regions of the NRPS genes (including the putative yersiniabactin cluster gene $h m w p 1)$ such that when they were fused no frame shift would result (all primers used in this study are listed in Additional file 1, Table S1). For deletion of acsA, which is much smaller, 400 bp regions immediately upstream and downstream of the gene, including the first and last 3 codons of the gene on either side, were amplified. The upstream primer of the 3' fragments contained a region complementary to the downstream primer of the 5' fragment for use in splice overlap extension (SOE) PCR [38]. The outer-most primers contained restriction enzyme sites to enable directional cloning of the spliced fragments into the suicide vector pDM4 [63], following which gene knockout was performed as described below.

For gene complementation studies we generated an IPTG-inducible broad-host range vector, pSX, by cloning the lacIQ gene, tac promoter and multiple cloning region of pMMB67EH [64] together with an artificiallyintroduced ribosome binding site into pUCP22 [65]. The full sequence of this plasmid is available on GenBank (accession number JN703735). Pspph1925 was PCR-amplified using the primers $1925 \mathrm{compFw}$ and 1925compRv (Supplementary Table 1) and directionally cloned into pSX via the introduced NdeI and HindIII 
restriction sites. The accuracy of this and all other plasmid gene inserts was validated by sequencing (Macrogen, Korea).

\section{Targeted deletion of $P$. syringae 1448a genes}

Mutagenic plasmids were delivered to $P$. syringae 1448 a using an electroporation protocol for Pseudomonas mutagenesis adapted from [38]. Overnight cultures were grown to stationary phase in LB media, then $6 \mathrm{ml}$ of culture were aliquoted into $1.5 \mathrm{ml}$ microfuge tubes for each electroporation. Cells were twice pelleted by centrifugation followed by resuspension in sterile $300 \mathrm{mM}$ sucrose to wash. After the final wash all cells were pelleted, resuspended and pooled in $100 \mu \mathrm{l}$ of $300 \mathrm{mM}$ sucrose and transferred to a $2 \mathrm{~mm}$ gap electroporation cuvette together with $10 \mu \mathrm{l}$ of mutagenic plasmid sample in $\mathrm{ddH}_{2} \mathrm{O}$. Following electroporation and recovery as described [66], $100 \mu \mathrm{l}$ samples were plated on LB containing chloramphenicol and rifampicin (P. syringae 1448 a is rifampicin resistant; this antibiotic was added to avoid growth of contaminants, not for selection of pDM4 chromosomal integrants). Plates were then incubated for $48-72 \mathrm{~h}$ at $28^{\circ} \mathrm{C}$. Subsequent selection of primary integrants and $s a c B$ counter-selection were performed as previously described [38], with the resulting colonies screened for desired mutation events by colony PCR. For pyoverdine NRPS knockouts, mutant genotypes were also confirmed by Southern blotting using an Amersham alkphos ${ }^{\circledR}$ kit with CDP Star ${ }^{\circledR}$ detection reagent according to the manufacturer's instructions.

\section{CAS agar assays for iron uptake}

$>100 \mathrm{ml}$ Chromeazurol S (CAS) dye for the detection of siderophores [67] was made by dissolving $60.5 \mathrm{mg}$ CAS powder (Sigma) in $50 \mathrm{ml}$ distilled water. To this $10 \mathrm{ml}$ of a $1 \mathrm{mM}$ solution of $\mathrm{FeCl}_{3}$ was added. The entire solution was then poured slowly with stirring into $40 \mathrm{ml}$ distilled water containing $72.9 \mathrm{mg}$ dissolved HDTMA (Sigma) and autoclaved to sterilize. To make agar plates, freshly autoclaved $\mathrm{KB}$ agar was cooled to $60^{\circ} \mathrm{C}$ before adding 1 part CAS dye to 9 parts media. Plates were immediately poured, and at this point exhibited a dark green color. Strains were inoculated into dried CAS plates by picking a large colony with a sterile $100 \mu \mathrm{l}$ pipette tip and piercing the tip approximately $5 \mathrm{~mm}$ into the surface of the agar plates. Plates were then incubated upside down at $28^{\circ} \mathrm{C}$ for $24 \mathrm{~h}$. After $24 \mathrm{~h}$ incubation the $22^{\circ} \mathrm{C}$ condition was removed from the incubator and maintained at $22^{\circ} \mathrm{C}$. Plates were photographed with minimal exposure to temperature change at 24, 48 and $72 \mathrm{~h}$. The entire assay was repeated three times; results presented in figures are from a single assay and are representative of all repeats.

\section{CAS media assays for iron uptake}

Strains were inoculated in triplicate into $200 \mu \mathrm{K}$ KB media in a 96-well plate to an initial OD600 of 0.1, with outer wells filled with sterile $\mathrm{H}_{2} \mathrm{O}$ to minimize evaporation. Replicate plates were then covered but not sealed and incubated for $24 \mathrm{~h}$ at $28^{\circ} \mathrm{C}$ or $22^{\circ} \mathrm{C}$ with shaking. The next day cells were pelleted by centrifugation $(4000$ g, $15 \mathrm{~min}$ ) and $150 \mu \mathrm{l}$ of supernatant was transferred to fresh wells in a flat bottomed 96-well plate. To each well $30 \mu \mathrm{l}$ of CAS dye (prepared as described above) was added using a multi channel pipette. Plates were immediately placed into the plate reader and OD 655 values recorded every $5 \mathrm{~min}$ for $50 \mathrm{~min}$, then again at $65 \mathrm{~min}$ and $125 \mathrm{~min}$.

\section{EDDHA Inhibitory Concentration $\left(\mathrm{IC}_{50}\right)$ assays}

A 2-fold serial dilution series of $\mathrm{KB}$ media containing from $200-0.195 \mu \mathrm{g} / \mathrm{ml}$ of the iron chelator EDDHA (ethylene-diamine-di(o-hydroxyphenylacetic acid); a generous gift from Dr Iain Lamont) was established in 96 well plates. Strains were inoculated in quadruplicate to an initial OD 600 of 0.1 from cultures synchronized by subinoculation over two nights, giving a final volume of 125 $\mu \mathrm{l}$ per well. Unsealed plates were then incubated for $24 \mathrm{~h}$ at $28^{\circ} \mathrm{C}$ or $22^{\circ} \mathrm{C}$ with shaking. Wells were diluted $1: 1$ with $\mathrm{KB}$ in order to be within the linear range of the plate reader, and OD 600 values were measured. For each temperature the assay was repeated twice with consistent results. Errors are presented as \pm 1 standard deviation.

\section{P. syringae 1448a pathogenicity tests in Phaseolus vulgaris} Single colonies from fresh $48 \mathrm{~h} \mathrm{~KB}$ agar plates were picked using a sterile hypodermic needle. Strains were then inoculated into snap bean pods (Phaseolus vulgaris) by piercing the surface of the bean approximately $5 \mathrm{~mm}$. Each strain was inoculated in triplicate together with a WT positive control. Bean pods were then placed in a sealed humid containers or alternatively, for on plant assessment, pods were left attached to parental plants growing indoors at $20-25^{\circ} \mathrm{C}$. Results were recorded every $24 \mathrm{~h}$. Development of water soaked lesions similar to those of WT strain was taken as a positive result. The assay was repeated in triplicate.

\section{Additional material}

Additional file 1: Table S1 - supplementary table of PCR primers employed in this study. A complete listing of all PCR primers employed in this work.

\section{Acknowledgements}

We are grateful to Professor John Mansfield (Imperial College, London) for providing us with the strain of $P$. syringae 1448a that was the subject of this 
study as well as for his many helpful suggestions for working with this strain. We also thank Professor lain Lamont (University of Otago, New Zealand) for his generous gift of EDDHA and for sharing his valuable time and advice. This work was supported by the Royal Society of New Zealand Marsden Fund [contract number VUW0901] and Victoria University of Wellington New Researcher and University Research Fund Grants to DFA. JGO was supported by a Victoria University of Wellington PhD Scholarship and subsequently by Marsden postdoctoral funding.

\section{Author details}

${ }^{1}$ School of Biological Sciences, Victoria University of Wellington, Kelburn Parade, PO Box 600, Wellington 6140, New Zealand. ${ }^{2}$ Howard Hughes Medical Institute, Laboratory of Genetically Encoded Small Molecules, The Rockefeller University, 1230 York Avenue, New York, NY 10065, USA.

\section{Authors' contributions}

JGO co-designed the project, conducted the majority of the hands-on experimental work, and helped to draft the manuscript. DFA was the primary investigator and co-designed the project, assisted with experimental work, offered technical advice, obtained all funding, and drafted the manuscript. Both authors read and approved the final manuscript.

Received: 3 August 2011 Accepted: 3 October 2011

Published: 3 October 2011

\section{References}

1. Braun V, Hantke K: Recent insights into iron import by bacteria. Curr Opin Chem Biol 2011, 15:328-334.

2. Cornelis P, Matthijs S: Diversity of siderophore-mediated iron uptake systems in fluorescent pseudomonads: not only pyoverdines. Environ Microbiol 2002, 4:787-798.

3. He J, Baldini RL, Déziel E, Saucier M, Zhang Q, Liberati NT, Lee D, Urbach J, Goodman HM, Rahme LG: The broad host range pathogen Pseudomonas aeruginosa strain PA14 carries two pathogenicity islands harboring plant and animal virulence genes. Proc Natl Acad Sci USA 2004, 101:2530-2535.

4. Höfte M, de Vos P: Plant pathogenic Pseudomonas species. In PlantAssociated Bacteria. Edited by: Gnanamanickam SS. Springer: New York; 2006:507-533.

5. Meyer J, Neely A, Stintzi A, Georges C, Holder I: Pyoverdin is essential for virulence of Pseudomonas aeruginosa. Infect Immun 2006, 64:518-523.

6. Visca P, Imperi F, Lamont IL: Pyoverdine siderophores: from biogenesis to biosignificance. Trends Microbiol 2007, 15:22-30.

7. Weber T, Rausch C, Lopez P, Hoof I, Gaykova V, Huson DH, Wohlleben W: CLUSEAN: A computer-based framework for the automated analysis of bacterial secondary metabolite biosynthetic gene clusters. J Biotechnol 2009, 140:13-17.

8. Ravel J, Cornelis P: Genomics of pyoverdine-mediated iron uptake in pseudomonads. Trends Microbiol 2003, 11:195-200.

9. Meyer J, Abdallah M: The fluorescent pigment of Pseudomonas fluorescens: biosynthesis, purification and physicochemical properties. $J$ Gen Microbiol 1978, 107:319-328.

10. Visca P, Imperi F, Lamont IL: Pyoverdine synthesis and its regulation in fluorescent pseudomonads. In Microbial Siderophores. Edited by: Varma A, Chincholkarpp SB. Springer: New York; 2007:135-163.

11. Budzikiewicz H: Siderophores of the Pseudomonadaceae sensu stricto (fluorescent and non-fluorescent Pseudomonas spp.). Prog Ch Org Nat Prod 2004, 87:81-237.

12. Smith E, Sims E, Spencer D, Kaul R, Olson M: Evidence for diversifying selection at the pyoverdine locus of Pseudomonas aeruginosa. J Bacteriol 2005, 187:2138-2147.

13. Tummler B, Cornelis P: Pyoverdine receptor: a case of positive Darwinian selection in Pseudomonas aeruginosa. J Bacteriol 187:3289-3292.

14. Wenzel SC, Muller R: Formation of novel secondary metabolites by bacterial multimodular assembly lines: deviations from textbook biosynthetic logic. Curr Opin Chem Biol 2005, 9:447-458.

15. Finking R, Marahiel MA: Biosynthesis of nonribosomal peptides. Annu Rev Microbiol 2004, 58:453-488.

16. Ackerley DF, Lamont IL: Characterization and genetic manipulation of peptide synthetases in Pseudomonas aeruginosa PAO1 in order to generate novel pyoverdines. Chem Biol 2004, 11:971-980.
17. Crosa JH, Walsh CT: Genetics and assembly line enzymology of siderophore biosynthesis in bacteria. Microbiol Mol Biol Rev 2002, 66:223-249.

18. Martin LW, Reid DW, Sharples KJ, Lamont IL: Pseudomonas siderophores in the sputum of patients with cystic fibrosis. Biometals 2011.

19. Ackerley DF, Caradoc-Davies TT, Lamont IL: Substrate specificity of the nonribosomal peptide synthetase PvdD from Pseudomonas aeruginosa. J Bacteriol 2003, 185:2848-2855.

20. Berti AD, Thomas MG: Analysis of achromobactin biosynthesis by Pseudomonas syringae pv. syringae B728a. J Bacteriol 2009, 191:4594-4604.

21. Wensing A, Braun SD, Büttner P, Expert D, Völksch B, Ullrich MS, Weingart $\mathrm{H}$ : Impact of siderophore production by Pseudomonas syringae pv. syringae $22 \mathrm{~d} / 93$ on epiphytic fitness and biocontrol activity against Pseudomonas syringae pv. glycinea 1a/96. Appl Environ Microbiol 2010, 76:2704-2711.

22. Schmelz S, Kadi N, McMahon SA, Song L, Oves-Costales D, Oke M, Liu H, Johnson KA, Carter LG, Botting CH, White MF, Challis GL, Naismith JH: AcsD catalyzes enantioselective citrate desymmetrization in siderophore biosynthesis. Nat Chem Biol 2009, 5:174-182.

23. Challis G: A widely distributed bacterial pathway for siderophore biosynthesis independent of nonribosomal peptide synthetases. Chembiochem 2005, 6:601-611.

24. Gulick AM: Ironing out a new siderophore synthesis strategy. Nat Chem Biol 2009, 5:143-144.

25. Franza T, Mahe B, Expert D: Erwinia chrysanthemi requires a second iron transport route dependent of the siderophore achromobactin for extracellular growth and plant infection. Mol Microbiol 2005, 55:261-275.

26. Bodilis J, Ghysels B, Osayande J, Matthijs S, Pirnay JP, Denayer S, De Vos D, Cornelis $P$ : Distribution and evolution of ferripyoverdine receptors in Pseudomonas aeruginosa. Environ Microbiol 2009, 11:2123-2135.

27. Winsor GL, van Rossum T, Lo R, Khaira B, Whiteside MD, Hancock REW, Brinkman FSL: Pseudomonas Genome Database: facilitating user-friendly, comprehensive comparisons of microbial genomes. Nucl Acids Res 37: D483-488.

28. Singh GM, Fortin PD, Koglin A, Walsh CT: Hydroxylation of the aspartyl residue in the phytotoxin syringomycin $\mathrm{E}$ : Characterization of two candidate hydroxylases AspH and SyrP in Pseudomonas syringae. Biochemistry 2008, 47:11310-11320.

29. Ghysels B, Dieu BT, Beatson SA, Pirnay JP, Ochsner UA, Vasil ML, Cornelis P. FpvB, an alternative type I ferripyoverdine receptor of Pseudomonas aeruginosa. Microbiology 2004, 150:1671-1680.

30. Moon CD, Zhang XX, Matthijs S, Schäfer M, Budzikiewicz H, Rainey PB: Genomic, genetic and structural analysis of pyoverdine-mediated iron acquisition in the plant growth-promoting bacterium Pseudomonas fluorescens SBW25. BMC Microbiol 2008, 8:7.

31. Mossialos D, Ochsner U, Baysse C, Chablain P, Pirnay JP, Koedam N, Budzikiewicz H, Fernández DU, Schäfer M, Ravel J, Cornelis P: Identification of new, conserved, non-ribosomal peptide synthetases from fluorescent pseudomonads involved in the biosynthesis of the siderophore pyoverdine. Mol Microbiol 2002, 45:1673-1685.

32. Challis GL, Ravel J, Townsend CA: Predictive, structure-based model of amino acid recognition by nonribosomal peptide synthetase adenylation domains. Chem Biol 2000, 7:211-224.

33. Rausch C, Weber T, Kohlbacher O, Wohlleben W, Huson DH: Specificity prediction of adenylation domains in nonribosomal peptide synthetases (NRPS) using transductive support vector machines (TSVMs). Nucleic Acids Res 2005, 33:5799-5808.

34. Stachelhaus T, Marahiel MA: Modular structure of genes encoding multifunctional peptide synthetases required for non-ribosomal peptide synthesis. FEMS Microbiol Lett 1995, 125:3-14.

35. Bultreys A, Gheysen I, Wathelet B, Schäfer M, Budzikiewicz H: The pyoverdins of Pseudomonas syringae and Pseudomonas cichorii. Z Naturforsch 2004, 59:613-618.

36. Jülich M, Taraz K, Budzikiewicz H, Geoffroy V, Meyer JM, Gardan L: The structure of the pyoverdin isolated from various Pseudomonas syringae pathovars. Z Naturforsch 2001, 56:687-694.

37. Horton R, Hunt H, Ho S, Pullen J, Pease L: Engineering hybrid genes without the use of restriction enzymes: gene splicing by overlap extension. Gene 1989, 77:61-68. 
38. Choi $\mathrm{KH}$, Schweizer $\mathrm{H}$ : An improved method for rapid generation of unmarked Pseudomonas aeruginosa deletion mutants. BMC Microbiol 2005, 5:30.

39. King EO, Ward MK, Raney DE: Two simple media for the demonstration of pyocyanin and fluorescein. J Lab Clin Med 44:301-307.

40. Owen JG, Copp JN, Ackerley DF: Rapid and flexible biochemical assays for evaluating 4'-phosphopantetheinyl transferase activity. Biochem J 2011, 436:709-717

41. Lopez-Lopez K, Hernandez-Flores JL, Cruz-Aguilar M, Alvarez-Morales A: In Pseudomonas syringae pv. phaseolicola expression of the $\operatorname{argK}$ gene, encoding the phaseolotoxin-resistant ornithine carbamoyltransferase, is regulated indirectly by temperature and directly by a precursor resembling carbamoylphosphate. J Bacterio/ 186:146-153.

42. Joardar V, Lindeberg M, Jackson RW, Selengut J, Dodson R, Brinkac LM, Daugherty SC, Deboy R, Durkin AS, Giglio MG, Madupu R, Nelson WC, Rosovitz MJ, Sullivan S, Crabtree J, Creasy T, Davidsen T, Haft DH, Zafar N, Zhou L, Halpin R, Holley T, Khouri H, Feldblyum T, White O, Fraser CM, Chatterjee AK, Cartinhour S, Schneider DJ, Mansfield J, Collmer A, Buell CR: Whole-genome sequence analysis of Pseudomonas syringae pv. phaseolicola $1448 \mathrm{~A}$ reveals divergence among pathovars in genes involved in virulence and transposition. J Bacterio/ 2005, 187:6488-6498.

43. Jones AM, Lindow SE, Wildermuth MC: Salicylic acid, yersiniabactin, and pyoverdin production by the model phytopathogen Pseudomonas syringae pv. tomato DC3000:synthesis, regulation, and impact on tomato and Arabidopsis host plants. J Bacteriol 2007, 189:6773-6786.

44. Fourie D: Characterization of halo blight races on dry beans in South Africa. Plant Dis 1998, 82:307-310.

45. Bultreys A, Gheysen I, Wathelet B, Maraite H, de Hoffmann E: Highperformance liquid chromatography analyses of pyoverdin siderophores differentiate among phytopathogenic fluorescent Pseudomonas species. Appl Environ Microbiol 2003, 69:1143-1153.

46. Jones AM, Wildermuth MC: The phytopathogen Pseudomonas syringae pv. tomato DC3000 has three high-affinity iron-scavenging systems functional under iron limitation conditions but dispensable for pathogenesis. J Bacteriol 2011, 193:2767-2775.

47. Garner BL, Arceneaux JEL, Byers BR: Temperature control of a 3,4dihydroxybenzoate (protocatechuate)-based siderophore in Bacillus anthracis. Curr Microbiol 2004, 49:89-94.

48. Colquhoun DJ, Sørum H: Temperature dependent siderophore production in Vibrio salmonicida. Microb Pathog 2001, 31:213-219.

49. Bachhawat AK, Ghosh S: Temperature inhibition of siderophore production in Azospirillum brasilense. J Bacteriol 1989, 171:4092-4094.

50. Bender $C L$, Alarcon-Chaidez F, Gross DC: Pseudomonas syringae phytotoxins: mode of action, regulation, and biosynthesis by peptide and polyketide synthetases. Microbiol Mol Biol Rev 63:266-292.

51. Expert D, Enard C, Masclaux C: The role of iron in plant host-pathogen interactions. Trends Microbiol 1996, 4:232-237.

52. Cody Y, Gross D: Outer membrane protein mediating iron uptake via pyoverdin, the fluorescent siderophore produced by Pseudomonas syringae pv. syringae. J Bacteriol 1987, 169:2207-2214.

53. Hirano SS, Upper CD: Bacteria in the leaf ecosystem with emphasis on Pseudomonas syringae-a pathogen, ice nucleus, and epiphyte. Microbiol Mol Biol Rev 2000, 64:624-653.

54. Matthijs S, Laus G, Meyer JM, Abbaspour-Tehrani K, Schäfer M, Budzikiewicz H, Cornelis P: Siderophore-mediated iron acquisition in the entomopathogenic bacterium Pseudomonas entomophila L48 and its close relative Pseudomonas putida KT2440. Biometals 2009, 22:951-964.

55. Cornelis P: Iron uptake and metabolism in pseudomonads. Appl Microbiol Biotechnol 2010, 86:1637-1645.

56. Braud A, Hoegy F, Jezequel K, Lebeau T, Schalk IJ: New insights into the metal specificity of the Pseudomonas aeruginosa pyoverdine-iron uptake pathway. Environ Microbiol 2009, 11:1079-1091.

57. Schalk IJ, Hannauer M, Braud A: New roles for bacterial siderophores in metal transport and tolerance. Environ Microbiol .

58. Matthijs S, Tehrani KA, Laus G, Jackson RW, Cooper RM, Cornelis P: Thioquinolobactin, a Pseudomonas siderophore with antifungal and antiPythium activity. Environ Microbiol 2007, 9:425-434.

59. Guenzi E, Galli G, Grgurina I, Gross DC, Grandi G: Characterization of the syringomycin synthetase gene cluster. A link between prokaryotic and eukaryotic peptide synthetases. J Biol Chem 1998, 273:32857-32863.
60. von Dohren H, Dieckmann R, Pavela-Vrancic M: The nonribosomal code. Chem Biol 1999, 6:R273-R279.

61. Arnold DL, Lovell HC, Jackson RW, Mansfield JW: Pseudomonas syringae pv. phaseolicola: from 'has bean' to supermodel. Mol Plant Pathol 2011, 12:617-627.

62. Meyer JM, Stintzi A, de Vos D, Cornelis P, Tappe R, Taraz K, Budzikiewicz H: Use of siderophores to type pseudomonads: the three Pseudomonas aeruginosa pyoverdine systems. Microbiol 1997, 143:35-43.

63. Milton $\mathrm{DL}$, OToole $\mathrm{R}$, Horstedt $\mathrm{P}$, Wolf-Watz $\mathrm{H}$ : Flagellin $\mathrm{A}$ is essential for the virulence of Vibrio anguillarum. J Bacteriol 1996, 178:1310-1319.

64. Fürste JP, Pansegrau W, Frank R, Blöcker H, Scholz P, Bagdasarian M, Lanka E: Molecular cloning of the plasmid RP4 primase region in a multihost-range tacP expression vector. Gene 1986, 48:119-131.

65. West SE, Schweizer HP, Dall C, Sample AK, Runyen-Janecky LJ: Construction of improved Escherichia-Pseudomonas shuttle vectors derived from pUC18/19 and sequence of the region required for their replication in Pseudomonas aeruginosa. Gene 1994, 148:81-86.

66. Choi KH, Kumar A, Schweizer H: A 10-min method for preparation of highly electrocompetent Pseudomonas aeruginosa cells: Application for DNA fragment transfer between chromosomes and plasmid transformation. J Microbiol Methods 2006, 64:391-397.

67. Schwyn B, Neilands J: Universal chemical assay for the detection and determination of siderophores. Anal Biochem 1987, 160:47-56.

\section{doi:10.1186/1471-2180-11-218}

Cite this article as: Owen and Ackerley: Characterization of pyoverdine and achromobactin in Pseudomonas syringae pv. phaseolicola 1448a. BMC Microbiology 2011 11:218.

\section{Submit your next manuscript to BioMed Central and take full advantage of:}

- Convenient online submission

- Thorough peer review

- No space constraints or color figure charges

- Immediate publication on acceptance

- Inclusion in PubMed, CAS, Scopus and Google Scholar

- Research which is freely available for redistribution 